\title{
Bikinin-like inhibitors targeting GSK3/Shaggy-like kinases: characterisation of novel compounds and elucidation of their catabolism in planta
}

\author{
Wilfried Rozhon 1,2,3* Wuyan Wang ${ }^{2,4}$, Franz Berthiller ${ }^{5}$, Juliane Mayerhofer ${ }^{1}$, Tingting Chen ${ }^{2}$, Elena Petutschnig ${ }^{1,6}$,
} Tobias Sieberer $^{3,7}$, Brigitte Poppenberger ${ }^{2,3}$ and Claudia Jonak ${ }^{1^{*}}$

\begin{abstract}
Background: Plant GSK-3/Shaggy-like kinases are key players in brassinosteroid (BR) signalling which impact on plant development and participate in response to wounding, pathogens and salt stress. Bikinin was previously identified in a chemical genetics screen as an inhibitor targeting these kinases. To dissect the structural elements crucial for inhibition of GSK-3/Shaggy-like kinases by bikinin and to isolate more potent compounds we synthesised a number of related substances and tested their inhibitory activity in vitro and in vivo using Arabidopsis thaliana.

Results: A pyridine ring with an amido succinic acid residue in position 2 and a halogen in position 5 were crucial for inhibitory activity. The compound with an iodine substituent in position 5, denoted iodobikinin, was most active in inhibiting BIN2 activity in vitro and efficiently induced brassinosteroid-like responses in vivo. Its methyl ester, methyliodobikinin, showed improved cell permeability, making it highly potent in vivo although it had lower activity in vitro. HPLC analysis revealed that the methyl residue was rapidly cleaved off in planta liberating active iodobikinin. In addition, we provide evidence that iodobikinin and bikinin are inactivated in planta by conjugation with glutamic acid or malic acid and that the latter process is catalysed by the malate transferase SNG1.

Conclusion: Brassinosteroids participate in regulation of many aspects of plant development and in responses to environmental cues. Thus compounds modulating their action are valuable tools to study such processes and may be an interesting opportunity to modify plant growth and performance in horticulture and agronomy. Here we report the development of bikinin derivatives with increased potency that can activate BR signalling and mimic BR action. Methyliodobikinin was 3.4 times more active in vivo than bikinin. The main reason for the superior activity of methyliodobikinin, the most potent compound, is its enhanced plant tissue permeability. Inactivation of bikinin and its derivatives in planta involves SNG1, which constitutes a novel pathway for modification of xenobiotic compounds.
\end{abstract}

Keywords: Brassinosteroid, GSK-3/shaggy-like kinase, Inhibitor, Protein phosphorylation, Signal transduction

\section{Background}

Brassinosteroids (BRs) are plant steroid hormones involved in many processes including cell expansion and division, pollen tube growth, vascular tissue development, senescence and modulation of stress responses [1]. Plants deficient in brassinosteroids display characteristic phenotypes including severe dwarfism, shortened

\footnotetext{
* Correspondence: wilfried.rozhon@wzw.tum.de; claudia.jonak@gmi.oeaw.ac.at ${ }^{1}$ GMI-Gregor Mendel Institute of Molecular Plant Biology, Austrian Academy of Sciences, Vienna Biocenter, Dr. Bohr-Gasse 3, Vienna 1030, Austria

Full list of author information is available at the end of the article
}

hypocotyls and round shaped dark green leaves. An analysis of Arabidopsis thaliana mutants showing such phenotypes revealed a number of enzymes crucial for production of BRs. Depending on the affected pathway these enzymes can be divided into two groups: the first is involved in general sterol biosynthesis (Figure 1) and includes DWF5 [2], STE1/DWF7 [3,4] and DWF1/CBB1 [5,6]. The second group includes DWF4 [7], CPD [8], DET2 [9], ROT3, CYP90D1 [10], BR6ox1 and BR6ox2 [11]. These enzymes are involved in the BR biosynthesis pathway that starts from the bulk sterol campesterol as a






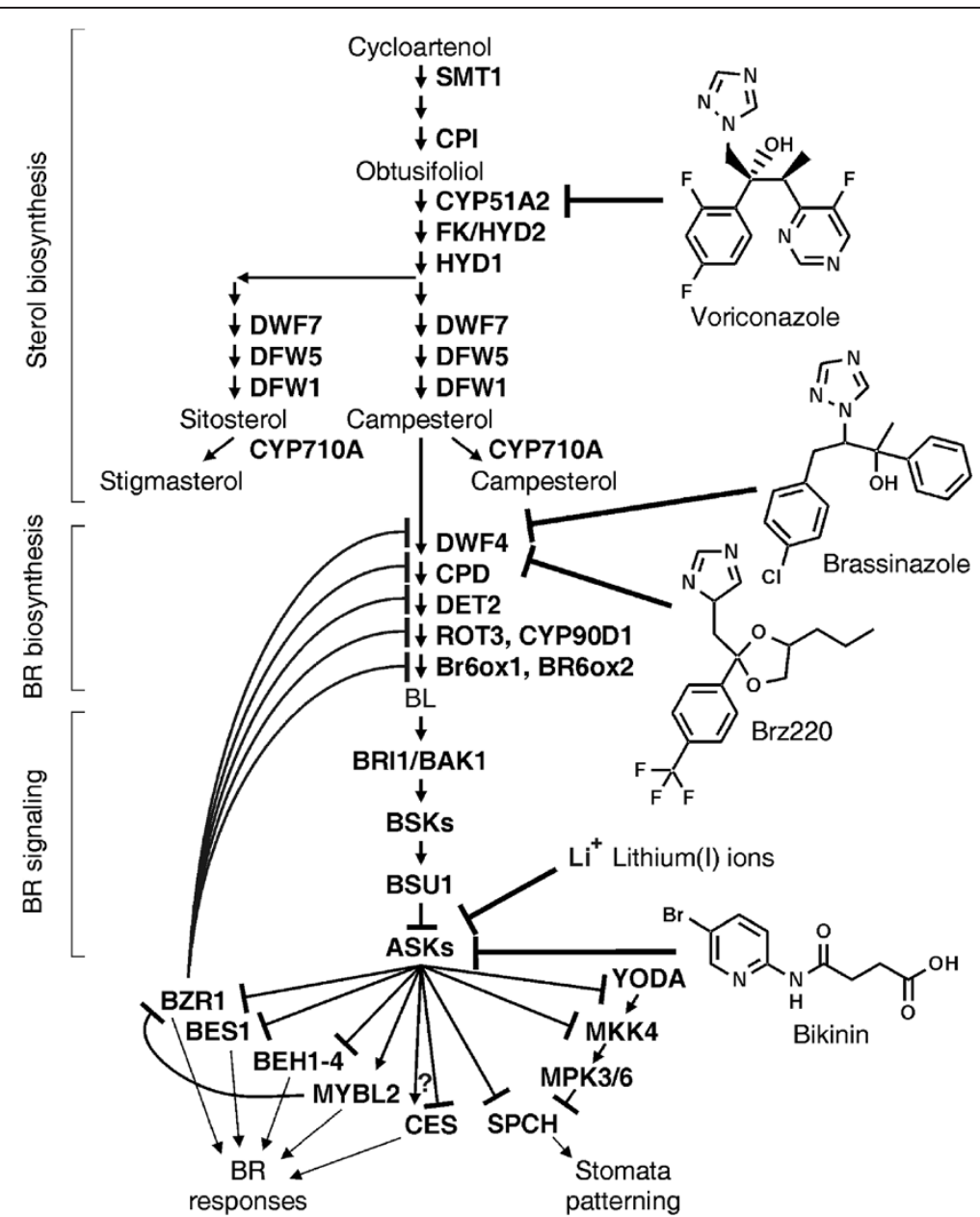

Figure 1 Targets of inhibitors interfering with sterol biosynthesis, BR biosynthesis and BR signal transduction.

precursor and ultimately yields brassinolide (BL), the most active BR (Figure 1). The expression of most enzymes of the BR synthesis pathway is negatively regulated by BR signalling while transcript levels of enzymes involved in general sterol biosynthesis are not BR responsive.

BL is perceived by the receptor kinase BRI1 [12] and its co-receptor BAK1 [13,14], which, unlike animal steroid receptors, localise to the cell membrane. The signal is transduced by the BSK group of receptor-like cytoplasmic kinases [15] and the phosphatase BSU1 [16] to ASKs, A. thaliana GSK-3/Shaggy-like kinases, which are inactivated in response to BL. ASKs are a family of serine/threonine protein kinases that can be grouped into four classes [17]. Several ASKs are involved BR signalling $[16,18-21]$, some ASKs have been shown to play a role in stress responses [22,23]. In the absence of $\mathrm{BL}$ the ASKs are active and can phosphorylate a number of transcription factors including BES1 [24], BZR1 [25] and their homologues BEH1 to BEH4 [26], MYBL2 [27], SPCH [28] and presumably also CES [29]. Interestingly, BIN2 (ASKn) and some other ASKs can also phosphorylate and thereby inactivate YODA [30] and MKK4 [31], two protein kinases acting in the MAP-kinase cascade that regulates SPCH activity. Similar to YODA and MKK4 most transcription factors are inhibited by BIN2-mediated phosphorylation. For instance, BES1 and BZR1 can only bind DNA in their unphosphorylated form to regulate gene expression [21].

Although a number of enzymes involved in sterol and BR synthesis and BR signalling are known, specific inhibitors are available only for a few of them (Figure 1). Recently, the triazole derivative voriconazole was shown to be a potent and specific inhibitor of plant CYP51s. Plants treated with this compound showed significantly reduced sterol and brassinosteroid levels and exhibited the typical signs of BR deficiency [32].

The observation that the gibberellic acid biosynthesis inhibitor uniconazole has a slight inhibitory effect on brassinosteroid biosynthesis led to the development of brassinazole [33] and Brz220 [34], two triazole derivatives (Figure 1) that target the heme iron of cytochrome P450 monooxygenase DWF4 [35,36]. Brassinazole has 
widely been used to study the synthesis and effects of brassinosteroids [37-41]. Furthermore, brassinazole was employed in genetic screens to isolate mutants that do not respond to this compound, which enabled the identification of the transcription factor BZR1 [25]. Several other inhibitors of sterol/BR biosynthesis are also known including Brz2001 [42], propiconazole [43], ketoconazole [44] and itraconazole [32]. However their molecular targets have remained elusive.

High concentrations of lithium ions $(\sim 10 \mathrm{mM})$ are used to inhibit the mammalian kinase GSK3 $\beta[45,46]$ and plant ASKs [47-49]. However, lithium(I) lacks specificity [50] and induces severe ion toxicity in plants [51-53], thus limiting its value for in vivo studies. Bikinin was identified by a chemical genetics approach as a compound that mimics BL treatment [54]. Bikinin is a non-steroidal compound that acts as an ATP-competitive inhibitor for plant GSK-3/ Shaggy-like kinases and thereby induces constitutive brassinosteroid responses. Bikinin is the monoamide of succinic acid with 2-amino-5-bromopyridine. The bromine in position 5 of the pyridine ring and the carboxylic acid group were recognised as being important for its activity [54]. However, a more detailed structure-activity relationship study to reveal the contribution of specific structural elements, for instance length of the aliphatic side chain and position of the heterocyclic nitrogen, is lacking and preliminary data indicated that substitution of bromine by other halogens might lead to more active compounds [54].

Here we studied the structural elements necessary for bikinin activity in more detail, which allowed us to isolate derivatives with enhanced activity and, importantly, increased cell-permeability. Moreover, we present evidence for the catabolic fate of bikinin and its derivatives after cellular uptake and identify a novel pathway for modification of xenobiotic compounds.

\section{Results \\ Synthesis}

To gain more insight into the structural elements important for bikinin activity and to further improve bikinin inhibitor potency, we synthesised a set of bikinin derivates. Bikinin and other derivatives were prepared by formation of amides from substituted aminopyridines and cyclic carboxylic acid anhydrides or chlorides of dicarboxylic acid monomethyl esters (Additional file 1). In the last case the methyl group was subsequently removed by alkaline hydrolysis, if required. Determination of the $\mathrm{pK}_{\mathrm{a}}$ of selected compounds revealed that they are weak acids (Additional file 1).

\section{In vitro inhibitor potency}

Bikinin is a potent inhibitor of group I and group II ASKs. ASK $\theta$, a group III ASK is moderately inhibited. The second kinase of this class, ASK $\beta$, and the group IV kinase
ASK $\delta$ are not inhibited [54]. To investigate the inhibitor activity of the set of bikinin derivates on ASK activity, representatives of all four ASK groups were expressed as recombinant GST fusion proteins in E. coli and the potency of the synthesised compounds (Figure 2) on the selected ASKs was assayed by in vitro kinase assays using the commonly used artificial substrate myeline basic protein (MBP) (Figure 3).

Compounds 1 to 5 were assayed to investigate the effect of length variation of the aliphatic side chain. The most active compound, no. 3, had a chain consisting of 4 carbons (Figure 2). The glutaryl (no. 4; five carbons) and the adipoyl (no. 5; six carbons) derivatives clearly had a lower potency while the shorter derivatives (no. 1 and 2; two and three carbons, respectively) had almost no effect. Introduction of a double bond into a side chain of optimal length abolished potency completely (Figure 3, compound 6 ) indicating that the steric conformation is highly important. To test whether the carboxy group of the aliphatic chain is essential for activity or if an oxo group is sufficient, we included compounds 9 and 10, which are the methyl esters of compounds 3 and 15, respectively. Compound 8 , a structural isomer of compound 3 , was also tested (Figure 2). As shown in Figure 3, the methylated variants showed dramatically reduced inhibitory effects confirming that a terminal carboxy group is essential.

Having identified the optimal side chain, we next investigated the influence of the heterocyclic ring in more detail. Compounds 3 and 11 both have an amido succinyl side chain but differ in the position of the heterocyclic nitrogen. In vitro kinase assays revealed that compound 3 is more potent (Figure 3), demonstrating that the heterocyclic nitrogen must be adjacent to the position carrying the amido succinic acid substituent.

Previous data indicated that a bromine substituent on position 5 of the pyridine ring is critical for biological activity of bikinin [54]. Compounds 12 to 16 were synthesised to test the effect of other substituents. As indicated in Figure 3 the chloro, bromo and especially the iodo derivative were highly active while the fluoro compound exhibited a very low potency. The unsubstituted and the nitro derivatives were inactive. Quantification of residual kinase activities showed that the inhibitory effect on BIN2 increased with the atomic number of the halogen substituent while an opposite but less pronounced effect could be observed for ASK $\theta$ (Additional file 2).

In summary, active derivatives inhibited ASK $\alpha$, BIN2 and ASK $\zeta$ strongly while ASK $\theta$ was moderately inhibited and their effects on ASK $\beta$ and ASK $\delta$ were negligible. Active compounds were characterised by an aliphatic $\mathrm{C}_{4}$ side chain with a terminal carboxy group and a heterocyclic nitrogen next to the amido group. In addition, a halogen substituent of the aromatic system was crucial. 


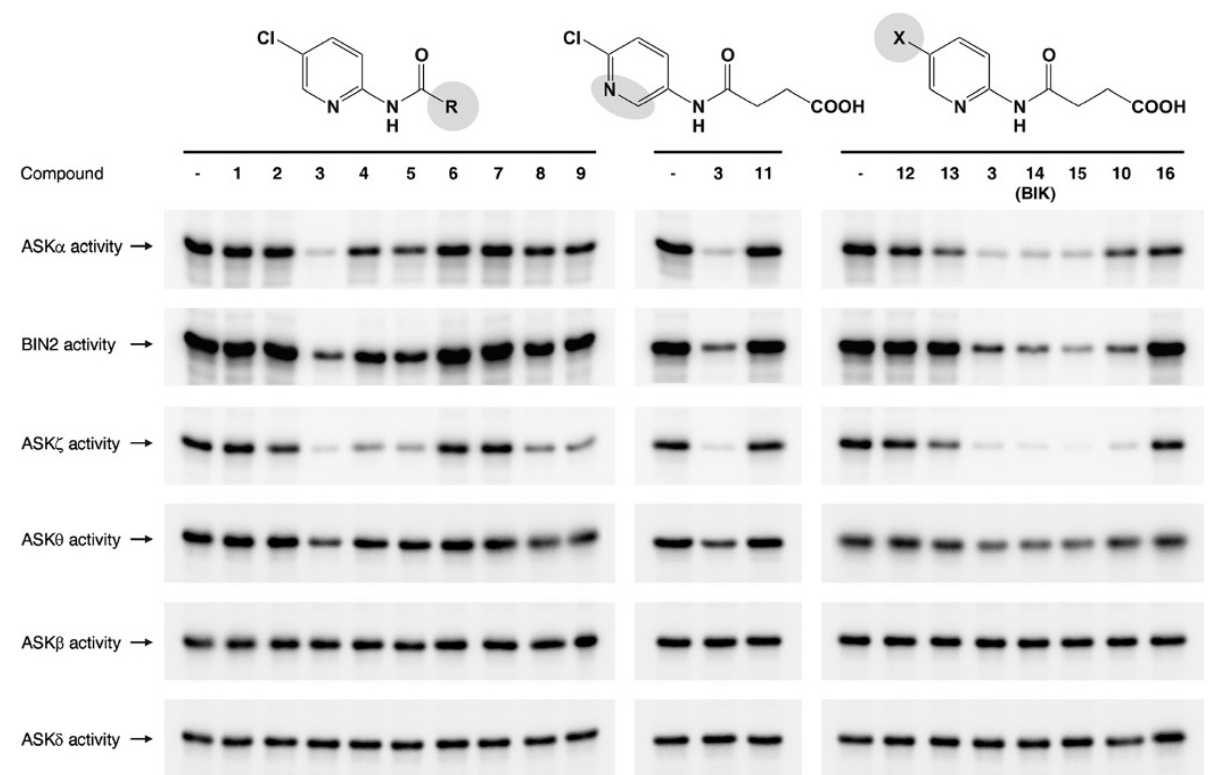

Figure 3 In vitro inhibitor activity. For ASK in vitro kinase assays, purified GST-ASK fusion proteins were incubated with MBP as a substrate and $\left[\gamma^{32} \mathrm{P}\right]-A T P$ as a co-substrate in absence $(-)$ or presence of $10 \mu \mathrm{M}$ of the different compounds (the numbers correspond to Figure 2). Compounds 1 to 9 (left panel) differ in the aliphatic side chain. The influence of the position of the heterocyclic nitrogen was tested with compounds 3 and 11 (middle panel; the molecular structure shown represents compound 11). The right panel shows the effect of the halogen substituent of the pyridine ring. BIK, bikinin. 
A fluoro residue had only a slightly promotive effect while the chloro, bromo and iodo derivatives were highly active.

\section{In vivo effects of the inhibitors}

Brassinosteroid deficient plants are severely dwarfed and display dark green, epinastic leaves and shortened hypocotyls. Application of 24-epi-brassinolide, a synthetic brassinosteroid, can partially rescue BR biosynthesis mutants like $c p d$ [8] but does not change the phenotype of BR signalling mutants like bri1-1 [55]. In contrast, bikinin can rescue both mutants partially [54]. To investigate the in vivo potency of the synthesised derivatives cpd and bri1-1 mutants were transferred to media supplemented with these compounds. Seedlings treated with active compounds showed expanded leaves, increased hypocotyl lengths and were light green. The potency to rescue the phenotype correlated with the results of the in vitro assay except for compounds 10 (Figure 4A) and 9 (data not shown), which showed little potency in vitro but were highly active in vivo. Because of this unexpected result we compared the bioactivities of compound 15 , which has a free carboxy group terminal at its aliphatic side chain, and of compound 10, which is the methylated counterpart. In addition, we also synthesised compound 18 , which is the methylated counterpart of bikinin (compound 14). To obtain quantitative data we measured the impact of these compounds on hypocotyl elongation of $A$. thaliana, an assay frequently used to investigate BR action $[6,9,56]$. The methylated compound 10 already showed a clear effect on hypocotyl length at $10 \mu \mathrm{M}$, while approximately $40 \mu \mathrm{M}$ of compound 15 were necessary to obtain comparable effects (Figure 4B). At such high concentrations compound 10 already showed toxic effects that impeded full hypocotyl elongation. Similarly, methylated compounds 9 and 18 showed a much higher biological activity than their unmethylated counterparts 3 and 14 (bikinin), respectively (Additional file 3). We also compared compound 10, the most active inhibior, and bikinin (compound 14). Compound 10 and bikinin had $\mathrm{IC}_{50}$ values (half maximal inhibitory concentrations) of 6.9 and $23.3 \mu \mathrm{M}$, respectively (Additional file $3 \mathrm{C}$ ), showing that compound 10 is 3.4 times more active in the hypocotyl eleongation assay than the original bikinin.

Next we wanted to investigate the potency of the methylated compounds at the molecular level. ASKs involved in $B R$ signalling downregulate the activity of BES1/BZR1-family transcription factors by phosphorylation. This modification causes an electrophoretic mobility shift allowing convenient detection of in vivo ASK activity by western blot analysis [20,24-26,54]. A thaliana seedlings expressing BZR1-CFP were treated with different concentrations of compound 10 and 15 and the BZR1 phosphorylation pattern was compared by western blot analysis with that of mock treated plants (Figure 4C). Both compounds were capable to inducing a shift of BZR1-CFP to its de-phosphorylated form. A comparable result was also obtained for plants expressing BES1-CFP (Data not shown). A similar shift was also seen in A. thaliana protoplasts co-transformed with constructs of CFP-tagged BZR1 and Myc-tagged ASK $\zeta$ after treatment with different concentrations of compounds 10 and 15 (Additional file 4).

Thus, surprisingly, the methylated derivatives 9, 18 and 10 showed similar or even higher activities in vivo than their free acid counterparts 3,14 and 15, respectively, although in in vitro kinase assays the methyl esters had a weaker effect on ASK activity.

\section{Methylated bikinin derivatives are rapidly hydrolysed in planta}

To investigate these conflicting results in more detail, we analysed the fate of compound 10 in vivo. Seedlings were infiltrated with compound 10 and plant extracts subsequently analysed by HPLC. Only trace amounts of 10 could be observed but a novel peak, designated P1, appeared (Figures 5A and B). This peak could be identified by its retention time and its UV spectrum as compound 15 (Figure 5 and Additional file 5) indicating that compound 10 is rapidly converted to the highly active compound 15 in planta and explaining the different potency of compound 10 in vitro and in vivo. Prolonged incubation led to formation of two additional peaks, designated P2 and P3 (Figure 5C and B). The spectra of these two compounds indicate that they are derived from 15 , most likely by modification of the aliphatic side chain. Similar results were obtained for the pairs $3 / 9$ and $14 / 18$ (data not shown).

\section{Tissue permeability of bikinin derivatives}

The previous result that the methylated compounds are rapidly hydrolysed to their corresponding active free acid forms provided an explanation for the observation that the methylated compounds showed little or no activity in vitro while they were highly active in vivo. However, this result could not explain why the methylated derivatives 10, 9 and 18 showed significantly higher in planta activities than their free acid counterparts 15, 3 and 14, respectively (Figure 4B and Additional file 3).

The cell-permeability of a substance is an important characteristic for its in vivo potency. Thus, we determined the uptake of compounds 10 and 15 by treatment of $A$. thaliana seedlings with the compounds and subsequent quantification of their internalised concentrations (Figure 6). Since compound 10 is rapidly converted to 15 , only the in situ concentration of the cleavage product, compound 15, was measured. Uptake of both compounds was rapid and the highest in situ concentrations were observed after 3 hours of treatment. It is important 





(See figure on previous page.)

Figure 4 In vivo effects of the inhibitors. (A) 7-day-old wild type A. thaliana seedlings, the brassinosteroid synthesis mutant cpd or the signalling mutant bri1-1 were transferred to $1 / 2$ MS medium containing $1 \mu \mathrm{M}$ 24-epi-brassinolide (24-epi-BL), $30 \mu \mathrm{M}$ compound 10 or $30 \mu \mathrm{M}$ compound 15 and incubated for 7 days under long day conditions. All pictures were taken with the same magnification. The size bar represents $1 \mathrm{~mm}$. (B) The hypocotyl length of 7-day-old A. thaliana Col-0 seedlings grown on 1/2 MS containing 1\% sucrose and supplemented with compound 10 or 15 at the indicated concentrations were measured. The means and standard deviations were calculated from at least 25 seedlings. (C) Plants expressing BZR1-CFP were treated with the indicated compound for $1 \mathrm{~h}$. Subsequently, the phosphorylation status of BZR1 was detected by western blot analysis using a GFP-antibody. A coomassie R250 stain is shown as loading control.

to note that the plant internal concentrations exceeded those of the medium. While $50 \mu \mathrm{M}$ were present in the medium, in situ concentrations of about $90 \mu \mathrm{M}$ were measured after treatment with compound 15 and more than $180 \mu \mathrm{M}$ after treatment with compound 10. These data show that the methylated inhibitor has an increased cellpermeability as compared to its unmethylated analogue, thus providing an explanation for the increased biological activity of the methylated inhibitors.

\section{Catabolic fate of bikinin derivatives}

After prolonged inhibitor treatment the in situ concentration of compound 15 declined (Figure 6), concomitant with the appearance of additional peaks that had already been observed in the previous experiment (Figure 5D and data not shown). According to the retention times and UV spectra, the same end products, P2 and P3, were obtained for compound 10 and 15 (data not shown).

Organisms can inactivate biologically active xenobiotic compounds by a number of reactions including hydrolysis, oxidation or conjugation with metabolites. However, it has also been reported that modification can activate a previously inactive compound [57]. In order to investigated whether the observed modification products of compound 10 , namely $\mathrm{P} 1$, which according to the previous results represents compound 15, and the two unknown compounds P2 and P3, are potent to inhibit ASKs, we purified the products by solid phase extraction and two fractionations by HPLC. As expected from the previous results (Figure 5 and Additional file 5), the UV spectra of the isolated products $\mathrm{P} 1, \mathrm{P} 2$ and $\mathrm{P} 3$ were nearly identical to that of the compounds 10 and 15 (data not shown) indicating that the chromophore, the pyridine ring including the halogen substituent and the amide bond, are still present in the products. This allowed quantification of P1, P2 and P3 by HPLC and UV detection. The potency of the isolated compounds was subsequently investigated by in vitro kinase assays (Figure 7). As previously determined, modification product P1 of compound 10 was highly potent to inhibit the kinase activity of BIN2. This was expected since P1 represents compound 15. In contrast, the modification products $\mathrm{P} 2$ and $\mathrm{P} 3$ had no impact on the activity of BIN2.
A possible modification mechanism that could explain at least one of the additional peaks would be shortening of the side chain by $\beta$-oxidation, a pathway which was first recognised by feeding experiments with synthetic $\omega$-phenyl fatty acids [58]. It has also been reported that the plant growth regulator indole-3-butyric acid is activated in planta to indole-3-acetic acid (IAA) by a process similar to $\beta$-oxidation [59]. To investigate whether P2 or P3 originate from such a process we synthesised compound 17, the expected $\beta$-oxidation end product of compound 15 (Additional file 5A). However, the retention time and the UV spectrum of compound 17 were distinct from that of P2 or P3 (Additional file 5B and C), ruling out this possibility.

To identify the metabolic products of compound 10, we analysed them by high resolution mass-spectrometry. Based on the obtained masses (Table 1) the only possible chemical formula are $\mathrm{C}_{9} \mathrm{H}_{9} \mathrm{IN}_{2} \mathrm{O}_{3}$ for P1, $\mathrm{C}_{13} \mathrm{H}_{13} \mathrm{IN}_{2} \mathrm{O}_{7}$ for $\mathrm{P} 2$ and $\mathrm{C}_{14} \mathrm{H}_{16} \mathrm{IN}_{3} \mathrm{O}_{6}$ for P3. This confirms that $\mathrm{P} 1$ is nearly identical to compound 15 . Since P2 and P3 are formed from $\mathrm{P} 1$ (=compound $15 ; \mathrm{C}_{9} \mathrm{H}_{9} \mathrm{IN}_{2} \mathrm{O}_{3}$ ) and their UV spectra are identical to that of compound 15, P2 and P3 are presumably the conjugates of compound 15 with glutamic $\left(\mathrm{C}_{5} \mathrm{H}_{9} \mathrm{NO}_{4}\right)$ and malic acid $\left(\mathrm{C}_{4} \mathrm{H}_{6} \mathrm{O}_{5}\right)$, respectively (Figure 8 ). The observation of a conjugate with glutamic acid was not surprising since the reaction of amino acids with the carboxyl group of xenobiotics is a widespread reaction in plants $[60,61]$. To provide additional evidence for the composition of $\mathrm{P} 2$ we hydrolysed an aliquot and performed amino acid analysis. In the chromatogram a peak corresponding to glutamic acid was clearly visible (Additional file 6), confirming that P2 is the conjugate of compound 15 with glutamic acid.

\section{SNG1 catalyses conjugation of bikinin derivatives with malate}

Intriguingly, besides the glutamic acid derivative we could also detect a conjugate of compound 15 with malic acid. While conjugates of xenobiotic compounds with malonic and pyruvic acid are common, conjugates with malic acid are less frequently observed [62] and the pathway for their formation remains elusive.

The structure of the malic acid derivative of compound 15 (Figure 8) resembles that of sinapoylmalate, one of the 


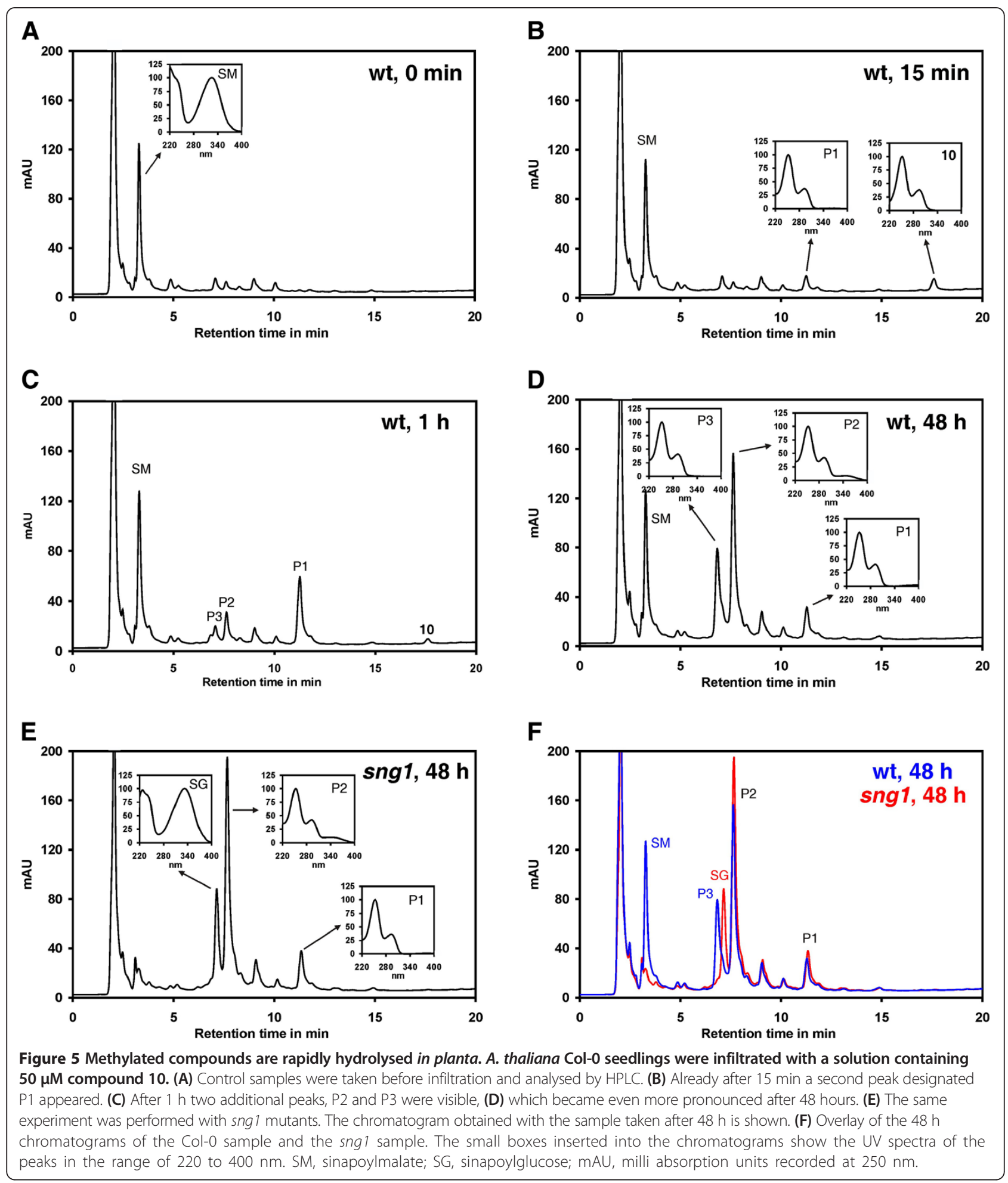

major soluble phenolic compounds present in A. thaliana. Sinapoylmalate is synthesised by glucosylation of sinapic acid by UGT84A2 and its homologues [63] and the subsequent exchange of the glucosyl residue to malate in a reaction catalysed by SNG1 [64]. Because of functional redundancy sinapoylglucose is still formed in ugt84a2 knock out plants [63]. In contrast, biosynthesis of sinapoylmalate is blocked in sng1 mutants. To assess whether the malate transferase SNG1 is necessary for generation of P3, we treated sng1 seedlings with compound 10 and 


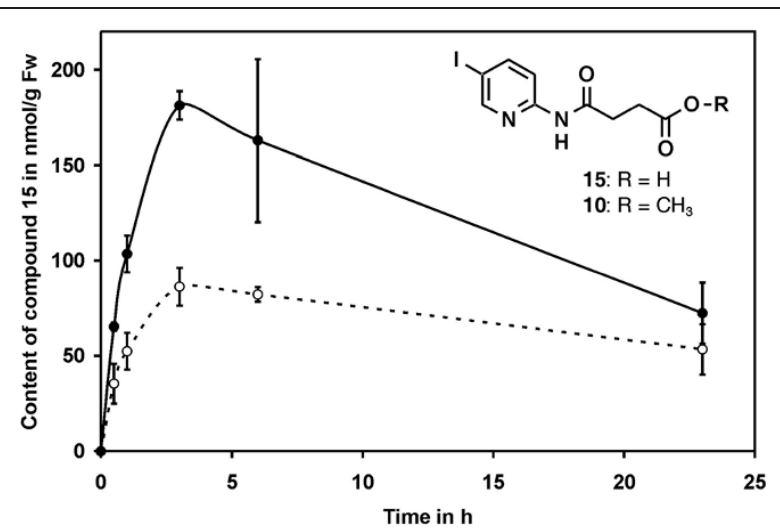

Figure 6 Methylation increases tissue-permeability. A. thaliana seedlings were incubated in $50 \mu \mathrm{M}$ solutions of compounds 10 and 15 in $1 / 2$ MS medium. Samples were taken after the indicated time and the in situ levels of compound 15 were analysed by HPLC. The solid line represents the results for plants incubated with compound 10 and the dashed line shows the results for compound 15 . The averages and standard deviations were calculated from 3 independent assays.

analysed the plant extract by HPLC. While the glutamic acid derivative P2 was still present, the malate derivative P3 was absent in plants deficient in SNG1 function (Figures 5E and F), confirming that SNG1 catalyses formation of the latter. In the chromatogram of the sng1 plants another peak appeared close to that of P3 while the pronounced peak present at a retention time of $3.5 \mathrm{~min}$ in extracts of Col-0 plants (see for instance Figure 5A) was absent. These peaks showed strong fluorescence (Additional file 7) and represent sinapoylglucose (retention time $7.5 \mathrm{~min}$ ) and sinapoylmalate (retention time $3.5 \mathrm{~min}$ ). In summary, this result demonstrates that SNG1 catalyses the conjugation of malate with compound 15 .

\section{Discussion}

Mutants are widely and successfully used to investigate different biological processes. The application of specific inhibitors is an interesting alternative approach that may offer several advantages compared to mutant analysis. Inhibitors can be used in different genetic backgrounds without the necessity for time consuming crossings. Often they are active in a wide range of organisms allowing investigation of species where no mutants are available. In addition, the application of inhibitors can be limited to a specific developmental stage. This is especially important if a mutant is lethal. For instance, cyp51 knock out plants die in early seedling stages [65] impeding dissection of the role of CYP51 at later developmental stages. This problem could be circumvented by using the specific CYP51 inhibitor voriconazole, which revealed that CYP51 is highly important for providing precursors for BR biosynthesis [32]. Another remarkable advantage of inhibitors is that they can provide an opportunity to overcome functional redundancy since homologous proteins are often targeted by the same compound. This is especially important for analysis of polyploid organisms but also for gene families. For instance, $A$. thaliana encodes 10 ASKs [17] with several of them involved in BR signalling [16,20]. While dominant gain of function mutants show severe dwarfism [18,19], knock out mutants of single or even several ASKs display no or only very slight phenotypes [21]. In contrast, plants treated with the ASK inhibitor bikinin show the typical signs of constitutive BR response including elongated hypocotyls and light-green leaves [54] indicating that most or all ASKs crucial for BR signalling are inhibited. As a consequence, bikinin has become a widely used and valuable tool for studying BR signalling. Bikinin was originally identified in a chemical genetics screen for compounds mimicking BR responses. In vitro kinase assays revealed that it inhibits ASK activity by competing for the kinase binding site with ATP. Docking simulations suggested that the heterocyclic nitrogen may form a hydrogen bond with the backbone amide nitrogen of a conserved valine residue (V118 in BIN2) located in the ATP binding site [54]. This suggests that the heterocyclic nitrogen is crucial for bikinin activity, which is in perfect agreement with our results. Compound 11, which differs from the highly active compound 3 only in the position of the heterocyclic nitrogen, was inactive as revealed by in vitro kinase assays. Previous results indicated that the activity of the compounds decreases with the atomic number of the halogen substituent in position 5 of the pyridine ring [54]. However, we found that the fluoro derivative (compound 12) showed little activity to inhibit any ASK while the chloro, bromo and iodo derivatives were highly potent (Figure 3 ). Interestingly, the inhibitory activity of the compounds on BIN2 increased slightly with the atomic number of the halogen substituent while an opposite although weaker effect was seen for ASK $\theta$ (Additional file 2). With respect to that it is important to note that previous docking predictions indicate that the residue interacting with bikinin is a methionine in BIN2 but a leucine in ASK $\theta$, which may explain the different potencies of the chloro, bromo and iodo derivatives for these ASKs.

Analysis of a series of compounds differing only in the length of the aliphatic side chain revealed that the inhibitory effect was highest with a side chain of 4 carbon atoms and a terminal carboxy group (Figure 3). Previous docking simulations indicated that the carboxy group is necessary for interaction with an arginine conserved in the ASKs (arginine R124 in BIN2) [54]. Since the carboxy group of the aliphatic chain of bikinin has a $\mathrm{pK}_{\mathrm{a}}$ of 5.6 (Additional file 1) it is negatively charged at the intracellular $\mathrm{pH}$. Thus it likely interacts with the positively charged arginine residue by ionic interactions. In agreement with that the methylated derivatives 9 and 10, which are uncharged at a physiological $\mathrm{pH}$, showed little 


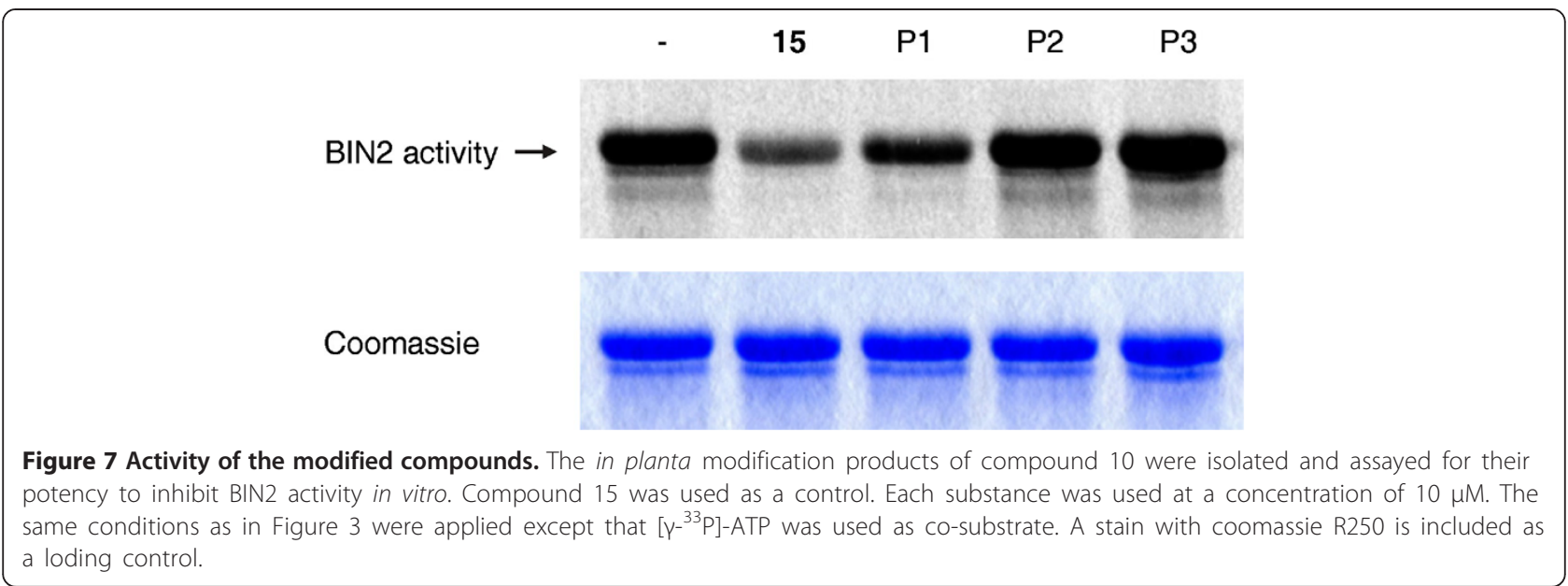

activity in vitro. In sharp contrast to in vitro assays, the methylated derivatives 9 and 10 were highly active in vivo and partially rescued BR mutants. Hypocotyl elongation, a typical response to BRs, was even more strongly induced by compounds 9,18 and 10 than their free acid counterparts 3, 15 and 14 (Figure 4B and
Additional file 3). In addition, dephoshorylation of BZR1, a widely used read out for BR signalling, was induced by the methylated compound 15 to a similar or higher extent than by the free acid compound 10, although only the latter was capable of inhibiting ASKs in vitro. The low in vitro effectiveness of the methylated

Table $1 \mathrm{UV}$ and high resolution mass spectrometry

\begin{tabular}{|c|c|c|c|}
\hline Compound & $\mathrm{UV}_{\max }[\mathrm{nm}]$ & $\mathrm{m} / \mathrm{z}$; deviation to the calculated $\mathrm{m} / \mathrm{z}$ in $\mathrm{ppm}$; ion type & Calculated formula for $[\mathrm{M}]$ \\
\hline \multirow[t]{6}{*}{10} & $250 / 292$ & 334.9892; 1.5; $[\mathrm{M}+\mathrm{H}]^{+}$ & $\mathrm{C}_{10} \mathrm{H}_{11} \mathrm{IN}_{2} \mathrm{O}_{3}$ \\
\hline & & $335.9921 ; 0.0 ;\left[{ }^{13} \mathrm{CM}+\mathrm{H}\right]^{+a}$ & \\
\hline & & $356.9708 ; 0.3 ;[\mathrm{M}+\mathrm{Na}]^{+}$ & \\
\hline & & $357.9742 ; 0.6 ;\left[^{13} \mathrm{CM}+\mathrm{Na}\right]^{+}$ & \\
\hline & & 209.0920; 0.5; [M-I + H $]^{+}$ & \\
\hline & & $210.0954 ; 0.0 ;\left[{ }^{13} \mathrm{CM}-\mathrm{I}+\mathrm{H}\right]^{+}$ & \\
\hline \multirow[t]{3}{*}{15} & $250 / 292$ & $320.9735 ; 1.2 ;[\mathrm{M}+\mathrm{H}]^{+}$ & $\mathrm{C}_{9} \mathrm{H}_{9} \mid \mathrm{N}_{2} \mathrm{O}_{3}$ \\
\hline & & $321.9764 ; 0.0 ;\left[{ }^{13} \mathrm{CM}+\mathrm{H}\right]^{+}$ & \\
\hline & & $342.9551 ; 0.3 ;[\mathrm{M}+\mathrm{Na}]^{+}$ & \\
\hline \multirow[t]{3}{*}{ P1 } & $251 / 292$ & $320.9734 ; 0.9 ;[\mathrm{M}+\mathrm{H}]^{+}$ & $\mathrm{C}_{9} \mathrm{H}_{9} \mid \mathrm{N}_{2} \mathrm{O}_{3}$ \\
\hline & & $321.9766 ; 0.6 ;\left[{ }^{13} \mathrm{CM}+\mathrm{H}\right]^{+}$ & \\
\hline & & 342.9552; 0.6; [M+ Na $]^{+}$ & \\
\hline \multirow[t]{6}{*}{ P2 } & $251 / 292$ & 450.0163; 1.3; $[\mathrm{M}+\mathrm{H}]^{+}$ & $\mathrm{C}_{14} \mathrm{H}_{16} \mathrm{IN}_{3} \mathrm{O}_{6}$ \\
\hline & & $451.0192 ; 0.4 ;\left[{ }^{13} \mathrm{CM}+\mathrm{H}\right]^{+}$ & \\
\hline & & 471.9978; 0.4; $[\mathrm{M}+\mathrm{Na}]^{+}$ & \\
\hline & & $473.0012 ; 0.4 ;\left[{ }^{13} \mathrm{CM}+\mathrm{Na}\right]^{+}$ & \\
\hline & & 324.1192; 0.6; [M-I + H $]^{+}$ & \\
\hline & & $325.1225 ; 0.3 ;\left[{ }^{13} \mathrm{CM}-\mathrm{I}+\mathrm{H}\right]^{+}$ & \\
\hline \multirow[t]{6}{*}{ P3 } & $251 / 292$ & $436.9846 ; 1.4 ;[\mathrm{M}+\mathrm{H}]^{+}$ & $\mathrm{C}_{13} \mathrm{H}_{13} \mathrm{IN}_{2} \mathrm{O}_{7}$ \\
\hline & & $437.9876 ; 0.5 ;\left[{ }^{13} \mathrm{CM}+\mathrm{H}\right]^{+}$ & \\
\hline & & $458.9662 ; 0.4 ;[\mathrm{M}+\mathrm{Na}]^{+}$ & \\
\hline & & $459.9695 ; 0.4 ;\left[{ }^{13} \mathrm{CM}+\mathrm{Na}\right]^{+}$ & \\
\hline & & $311.0874 ; 0.6 ;[M-I+H]^{+}$ & \\
\hline & & 312.0907; 0.6; $\left[{ }^{13} \mathrm{CM}-\mathrm{I}+\mathrm{H}\right]^{+}$ & \\
\hline
\end{tabular}




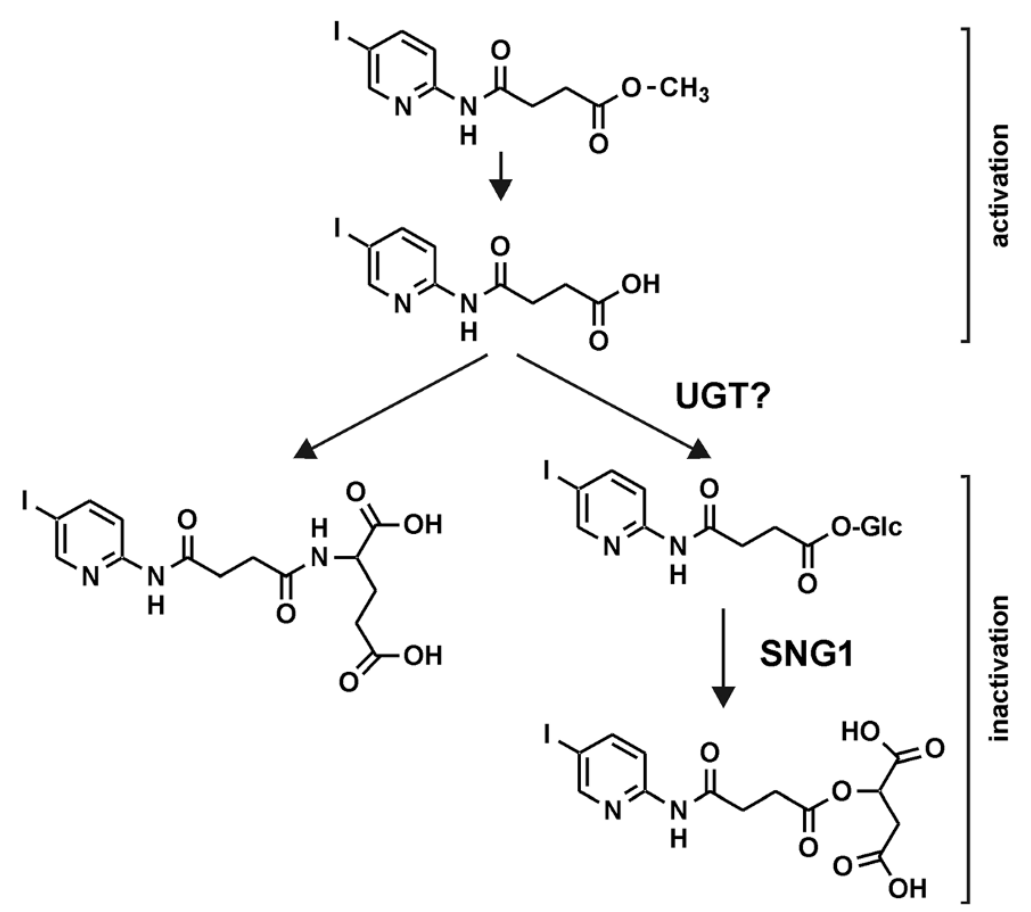

Figure 8 The catabolic fate of compound 10 in A. thaliana. Compound 10 is rapidly hydrolysed, likely by a lipase, and thereby activated to compound 15. Subsequently, compound 15 is inactivated by conjugation with glutamic acid or with malate. The latter reaction is catalysed by SNG1. Since SNG1 utilises glucosylated substrates compound 15 is presumably glucosylated by a UGT prior to SNG1-mediated conjugation with malate.

inhibitors on the one hand and their high in vivo potency on the other hand is likely due to their high cellular permeability and the rapid cleavage of the methyl residue in planta, probably by a lipase (peak P1 in Figure 5).

Cellular uptake is a key factor determining inhibitor potency. Tissue permeability assays revealed that uptake of the compounds, especially methylated ones, was rapid. Interestingly, the in situ concentrations exceeded that of the surrounding medium several fold. This can be explained by the $\mathrm{pK}_{\mathrm{a}}$ values of the compounds (Additional file 1). For instance, derivative 15 has a $\mathrm{pK}_{\mathrm{a}}$ value of 5.8, which means that at $\mathrm{pH} 5.8$, the $\mathrm{pH}$ of the medium used, $50 \%$ of the compound are dissociated and therefore negatively charged while $50 \%$ are undissociated. At the intracellular $\mathrm{pH}$ of approximately 7.4 [66] less than $3 \%$ of the compound is undissociated. Since only the undissociated, lipophilic form is expected to pass biomembranes efficiently, the compounds are trapped in the cell and accumulate to concentrations exceeding that of the surrounding medium. This $\mathrm{pH}$-dependent uptake resembles that of the plant hormone auxin, where $\mathrm{pH}$-driven diffusion has been suggested to contribute to transport into the cell [67]. The esterified compounds, for instance compound 10, are independent of the $\mathrm{pH}$, highly lipophilic and can pass membranes. In the cell they are rapidly hydrolysed to the corresponding acids, which deprotonate to hydrophilic anions. It is interesting to note that the uptake rate of compound 10 was roughly double that of compound 15, which correlates with the portions capable of diffusion through the membrane: while $100 \%$ of compound 10 are lipophilic, only $50 \%$ of compound 15 are undissociated and therefore sufficiently lipophilic.

After prolonged incubation the in situ levels of compound 15 declined, which was accompanied by the appearance of two peaks designated P2 and P3. The UV spectra of these peaks were nearly identical to that of 15 , indicating that they contain the same chromophore, namely the pyridine ring with the amido bond and the halogen substituent. This, together with chemical formulas determined by high resolution mass spectrometry, revealed that P2 and P3 represent the glutamic and malic acid derivatives of compound 15 , respectively. While conjugation of xenobiotic compounds with amino acids is a common phenomenon [68], the formation of a conjugate with malic acid was intriguing. The structure of the produced conjugate shows similarity to that of sinapoylmalate and thus we speculated that both compounds might be formed by the same enzyme. Indeed, formation of the malate conjugate of compound 15 was abolished in the sng1 mutant (Figures 5E and F). SNG1 is a transferase catalysing the formation of sinapolymalate 
from sinapoylglucose by exchange of the sugar residue for malic acid. This suggests that compound 15 is glucosylated in planta prior to conjugation with malic acid (Figure 8) although we could not observe glucosylated compound 15 in the chromatogram. In this respect it is worth noting that sinapoylglucose is hardly detectable in Col-0 plants since, once formed, the glucose residue is immediately exchanged to malate by SNG1, indicating that, in a similar manner to sinapoylglucose, glucosylated compound 15 might be rapidly metabolised.

\section{Conclusion}

The compounds 3,14 and 15, were highly potent in vitro with the iodo derivative (compound 15) showing the highest inhibitory effect on BIN2 and the chloro derivative (compound 3) being most active against ASK $\theta$. In vivo the methylated counterparts were more active, since they were significantly better taken up by plants and were immediately hydrolysed in planta to the active compounds. Thus, we propose the methylated derivatives of bikinin as inhibitors of choice for in vivo studies, especially if a rapid inhibition of ASKs is desired. Bikinin and its derivates are only temporarily active in plants which might be useful to dissect the role of ASK in a defined time window. The inactivation of the inhibitors by conjugation with malate involving SNG1 represents a novel pathway for modification of xenobiotic compounds and opens up new directions for studying the fate of xenobiotics in plants.

\section{Methods}

\section{Synthesis of the compounds}

The compounds were synthesised by reaction of amines with carboxylic acid anhydrides or chlorides using the methods described below. The reaction compounds and yields of the products are listed in Additional file 1.

Method A: A solution of $25 \mathrm{mmol}$ dicarboxylic acid anhydride dissolved in $15 \mathrm{ml}$ tetrahydrofuran $(10 \mathrm{ml}$ for phthalic anhydride) was placed in a round bottom flask equipped with a reflux condenser and $20 \mathrm{mmol}$ amine dissolved in $10 \mathrm{ml}$ tetrahydrofuran was added. The mixture was refluxed for 2 hours. The product started to crystallise at the end of the reaction. Crystallisation was completed by cooling to $4^{\circ} \mathrm{C}$ for several hours. The crude product was filtered with suction and recrystallised from 95\% ethanol except for the phthalic acid derivative, which was recrystallised from $80 \%$ acetonitrile.

Method B: A solution of $20 \mathrm{mmol}$ 2-amino-5-nitropyridine dissolved in $30 \mathrm{ml}$ tetrahydrofuran was placed in a round bottom flask and $25 \mathrm{mmol}$ solid succinic anhydride was added. A reflux condenser was fitted to the flask and the mixture heated to gentle boiling for 2 hours. Subsequently, the reaction mixture was cooled to $-20^{\circ} \mathrm{C}$ for several days. The crude product was filtered with suction and recrystallised from hot water.
Method C: $20 \mathrm{mmol}$ amine was dissolved in a mixture of $40 \mathrm{ml}$ tetrahydrofuran and $3.5 \mathrm{ml}(25 \mathrm{mmol})$ triethylamine and placed in a triple-necked round bottom flask equipped with a reflux condenser, a dropping funnel and a thermometer. The reaction mixture was agitated by magnetic stirring. A solution of $21 \mathrm{mmol}$ acid chloride dissolved in $10 \mathrm{ml}$ tetrahydrofuran was added slowly through the dropping funnel at such a rate that the temperature did not rise above $40^{\circ} \mathrm{C}$. After the chloride had been completely added, the reaction was stirred for further 15 minutes at room temperature. Subsequently, the mixture was poured into $200 \mathrm{ml}$ cold water and the $\mathrm{pH}$ set to 6 with diluted hydrochloric acid. The product was extracted three times with $50 \mathrm{ml}$ diethylether and the combined etheral extracts were washed with $50 \mathrm{ml} 1 \%$ acetic acid. Residual water was removed with anhydrous sodium sulphate prior evaporation of the ether under reduced pressure. The yellowish residue was recrystallised from 95\% ethanol (chloro derivatives) or toluene (iodo derivative) to yield an almost white product.

Method D: $21 \mathrm{mmol}$ acid chloride was dissolved in $10 \mathrm{ml}$ tetrahydrofuran and added to a solution of $20 \mathrm{mmol} 2$ amino-5-chloropyridine in $3.5 \mathrm{ml}$ ( $25 \mathrm{mmol})$ triethylamine and $40 \mathrm{ml}$ tetrahydrofuran as described in method $\mathrm{C}$. The mixture was stirred for 15 minutes prior to filtration to remove the triethylamine hydrochloride. The solid was washed with $10 \mathrm{ml}$ tetrahydrofuran and the combined filtrates evaporated under reduced pressure.

In the case of the oxalyl derivate, the residue was dissolved in $90 \mathrm{ml}$ hot $95 \%$ ethanol and the solution was filtered while still hot. The mixture was stirred and $40 \mathrm{mmol}$ $\mathrm{KOH}$ dissolved in $10 \mathrm{ml}$ water was added at such a rate that the temperature did not rise above $40^{\circ} \mathrm{C}$. The reaction was completed by stirring for a further 10 minutes. The product separated as white potassium salt, which was collected by suction. The precipitate was dissolved in $100 \mathrm{ml}$ (iodo derivative: $250 \mathrm{ml}$ ) hot water and filtrated. Hydrochloric acid was added to the hot filtrate until reaching $\mathrm{pH} 2$. The product separated as free acid during incubation at $4^{\circ} \mathrm{C}$ overnight. The product was further purified by recrystallisation from $95 \%$ ethanol.

In the case of the malonyl and adipoyl derivatives, the residue was dissolved in $200 \mathrm{ml} \mathrm{MeOH}$ and filtrated. The solution was placed in a triple-necked round bottom flask equipped with a reflux condenser, a dropping funnel and a thermometer and heated to $50^{\circ} \mathrm{C}$. While stirring the mixture, $40 \mathrm{mmol} \mathrm{KOH}$ dissolved in $40 \mathrm{ml}$ water was rapidly added through the dropping funnel while the temperature was maintained at $50^{\circ} \mathrm{C}$. The reaction was completed by stirring at the same temperature for an additional 10 minutes. The surplus of $\mathrm{KOH}$ was neutralised by the addition of $40 \mathrm{mmol} \mathrm{NH}_{4} \mathrm{Cl}$ dissolved in $10 \mathrm{ml}$ water. Most of the solvent was removed under reduced pressure and the residue was dissolved in water (about $200 \mathrm{ml}$ ) and 
filtered. Formic acid was added to the clear filtrate until reaching $\mathrm{pH} 3$. The product separated as white crystals during incubation at $4^{\circ} \mathrm{C}$ overnight. The malonyl and adipoyl derivatives were purified by recrystallisation from $95 \%$ or $50 \%$ ethanol, respectively.

\section{Determination of $\mathrm{pK}_{\mathrm{a}}$ values}

Fifty to $100 \mathrm{mg}$ of each compound were weighed and dissolved in $50 \mathrm{ml} 50 \%(\mathrm{v} / \mathrm{v})$ methanol. A titration curve with a $50 \mathrm{mM} \mathrm{NaOH}$ standard solution was recorded with a Greisinger Electonics GPHR 1400A pH meter. The equivalence point was determined by the difference quotient method $\left(\Delta \mathrm{pH} / \Delta \mathrm{V}_{\mathrm{NaOH}}\right)$ and the $\mathrm{pK}_{\mathrm{a}}$ read from the titration curve at $50 \%$ neutralisation.

\section{In vitro kinase assays}

ASKs were expressed as GST-fusion proteins in Escherichia coli BL21 as described previously [55]. In vitro kinase assays were performed by incubating $50 \mathrm{ng}$ GST-fusion protein, $10 \mu \mathrm{g}$ myelin basic protein (MBP; Sigma, St Louis, $\mathrm{MO})$ as a substrate and $0.15 \mathrm{MBq} \gamma-\left[{ }^{32} \mathrm{P}\right]$-ATP as cosubstrate at $25^{\circ} \mathrm{C}$ for $30 \mathrm{~min}$. The reaction buffer consisted of $20 \mathrm{mM}$ HEPES/KOH pH 7.4, $15 \mathrm{mM} \mathrm{MgCl}_{2}, 5 \mathrm{mM}$ EGTA, $1 \mathrm{mM}$ dithiothreitol and $1 \mu \mathrm{M}$ cold ATP. The reaction products were separated by SDS-PAGE and the amount of radioactivity incorporated into MBP quantified using an Amersham storage phosphor imager screen and a Biorad Molecular Imager FX.

\section{Physiological tests}

Arabidopsis thaliana Col-0 or bri1-1 seedlings were grown aseptically on $1 / 2$ Murashige and Skoog (MS) plates containing $0.8 \%$ agar and $1 \%$ sucrose in a growth camber under long day conditions $(16 \mathrm{~h}$ cool white fluorescent light at a photon flux of $80 \mu \mathrm{mol} \cdot \mathrm{m}^{-2} \cdot \mathrm{s}^{-1}$, $8 \mathrm{~h}$ dark) at $21^{\circ} \mathrm{C}$ for 7 days. Subsequently, they were transferred to plates supplemented with inhibitors in different concentrations and effects on the phenotype were observed 7 days later. For hypocotyl measurements Col0 seeds were plated on $1 / 2$ MS plates containing the indicated compounds, incubated at $4^{\circ} \mathrm{C}$ in the dark for 2 day for stratification and subsequently transferred to long day conditions. After 6 day hypocotyl length was measured using an Olympus SZX10 microscope at 10-fold magnification.

\section{Generation of lines transgenic for CFP tagged versions of BZR1 or BES1}

A. thaliana plants were transformed with the constructs pGWR8-BZR1-CFP or pGWR8-BES1-CFP [20] by the floral dip method [56]. For each transgene one line with a representative subcellular BZR1 or BES1 expression pattern was selected from at least 20 independent lines.

\section{Western blot analysis}

Plants transgenic for BZR1-CFP or BES1-CFP grown for 10 day on $1 / 2$ MS medium containing $1 \%$ sucrose were transferred to liquid medium and treated with the indicated compounds for $2 \mathrm{~h}$. Harvested samples (50 mg) were shock-frozen in liquid nitrogen, homogenized with a Retsch mill and after addition of $200 \mu \mathrm{l}$ extraction buffer (62.5 mM TRIS pH 6.8, 125 mM DTT, 2.5\% SDS, $12.5 \%$ glycerol, $0.01 \%$ bromophenol blue) immediately incubated at $95^{\circ} \mathrm{C}$ for $2 \mathrm{~min}$. The samples were centrifuged at $15000 \mathrm{~g}$ for $5 \mathrm{~min}$ and $10 \mu \mathrm{l}$ of the supernatants separated by SDS-PAGE (10\% gel) and blotted onto a polyvinylidene difluoride membrane (Millipore, Billerica, MA). The membrane was blocked with blocking buffer (5\% skim milk powder dissolved in $0.05 \%$ Tween 20 , $150 \mathrm{mM} \mathrm{NaCl}$ and $10 \mathrm{mM}$ TRIS/HCl pH 8.0) and subsequently probed with anti-GFP antibody (Roche, Basel, Switzerland) diluted 1:5000 in blocking buffer. Alkaline phosphatase-conjugated goat anti-mouse Fab specific fragment (Sigma-Aldrich, St. Louis, MO, USA) diluted 1:5000 with blocking buffer was employed as secondary antibody. For detection the CDP-Star ${ }^{\mathrm{Tm}}$ detection reagent (GE Healthcare, Buckinghamshire, UK) was used.

Protoplasts were transformed as described previously [57] and treated with the indicated compounds for $1 \mathrm{~h}$. After centrifugation, the protoplasts were lysed by adding $10 \mu \mathrm{l} 4 \times$ SDS loading buffer to $30 \mu \mathrm{l}$ protoplast suspension and immediately heated to $95^{\circ} \mathrm{C}$ for $2 \mathrm{~min}$. Western blot analysis was performed as described above except that $20 \mu \mathrm{l}$ protein extract were used for SDS-PAGE.

\section{Analysis of plant extracts by HPLC}

Two-week-old $A$. thaliana Col-0 seedlings were vacuum infiltrated with $1 / 2 \mathrm{MS}$ or $1 / 2 \mathrm{MS}$ containing $50 \mu \mathrm{M}$ compound 10 as described previously [58]. Samples were taken at the indicated time points, rinsed with water and ground in liquid nitrogen to a fine powder. $100 \mathrm{mg}$ powder was weighed into a reaction tube and $1 \mathrm{ml}$ extraction buffer (20\% acetonitrile (ACN) containing $20 \mathrm{mM}$ TRIS/ $\mathrm{HCl} \mathrm{pH} \mathrm{6.8)} \mathrm{was} \mathrm{added.} \mathrm{After} \mathrm{incubation} \mathrm{for} 30 \mathrm{~min}$ in a shaker set to $800 \mathrm{rpm}$, the mixture was centrifuged and the supernatant passed through a $0.2 \mu \mathrm{m}$ filter and analysed by HPLC. The HPLC system comprised a Dionex P680 pump, an ASI-100 autosampler and a PDA-100 photodiode array detector. The system was equipped with a $250 \times 4 \mathrm{~mm}$ Nucleosil $100-5 \mathrm{C}_{18} 250 \times 4 \mathrm{~mm}$ column (Macherey-Nagel, Düren, Germany) preceded by a Valco $2 \mu \mathrm{m}$ inline-filter. A constant flow rate of $1 \mathrm{ml} / \mathrm{min}$ was maintained with a gradient of solvent A (20 mM acetic acid set to $\mathrm{pH} 4.8$ with $\mathrm{NaOH}$ in $15 \% \mathrm{ACN}$ ) and solvent $\mathrm{B}$ (20 mM acetic acid set to $\mathrm{pH} 4.8$ with $\mathrm{NaOH}$ in $60 \%$ $\mathrm{ACN})$. Elution began with an isocratic flow of solvent $\mathrm{A}$ for $1 \mathrm{~min}$. The concentration of solvent $\mathrm{B}$ was then raised 
linearly to $100 \%$ within $19 \mathrm{~min}$ and kept isocratic for another $2 \mathrm{~min}$ prior to reducing it to $0 \%$ within $1 \mathrm{~min}$. The column was equilibrated for 5 min with solvent A before injection of the next sample. The UV spectra were recorded from 220 to $400 \mathrm{~nm}$ with $1 \mathrm{~nm}$ intervals. For quantification the absorbance at $250 \mathrm{~nm}$ with a bandwidth of $10 \mathrm{~nm}$ was recorded.

\section{Cell-permeability assay}

Two-week-old $A$. thaliana Col-0 seedlings were transferred to liquid $1 / 2 \mathrm{MS}$ medium containing $50 \mu \mathrm{M}$ inhibitor. Samples were removed after the indicated time points, rinsed twice with water, dried with filter paper and frozen in liquid nitrogen. For analysis the plant material was ground to a fine powder in a mortar pre-cooled with liquid nitrogen. Approximately $100 \mathrm{mg}$ powder was weighed into $1.5 \mathrm{ml}$ reaction tubes and $1 \mathrm{ml} 20 \mathrm{mM}$ TRIS/HCl pH 8.0 added. $50 \mu \mathrm{l}$ of a $200 \mu \mathrm{M}$ stock of compound 4 was added as internal standard. Extraction was performed at $80^{\circ} \mathrm{C}$ for $30 \mathrm{~min}$ in an Eppendorf thermo mixer set to $800 \mathrm{rpm}$. The extract was centrifuged for $5 \mathrm{~min}$ at $15000 \mathrm{~g}$ and the clear supernatant was collected. The clear solution was acidified by addition of $25 \mu \mathrm{l} 4 \mathrm{M}$ phosphoric acid and centrifuged for $2 \mathrm{~min}$ at $15000 \mathrm{~g}$. The supernatant was loaded immediately onto a PH $100 \mathrm{mg}$ solid-phase-extraction cartridge (Varian, Lake Forest, CA) conditioned with $1 \mathrm{ml} \mathrm{ACN}$ and two times $1 \mathrm{ml} 100 \mathrm{mM}$ phosphoric acid. Columns were washed with $1 \mathrm{ml} 100 \mathrm{mM}$ phosphoric acid and dried by applying vacuum for $1 \mathrm{~min}$. Subsequently, elution was performed with $1 \mathrm{ml} 100 \mathrm{mM}$ TRIS/HCl pH 9.0 containing 5\% ACN. The eluate was acidified by addition of $15 \mu \mathrm{l} 4 \mathrm{M}$ phosphoric acid and used for HPLC as described above.

\section{Isolation of modified compounds}

Two-week-old A. thaliana Col-0 seedlings (600 mg) were transferred to liquid $1 / 2$ MS medium and compound 15 was added to a final concentration of $50 \mu \mathrm{M}$. After $48 \mathrm{~h}$ incubation the plant material was collected, ground in liquid nitrogen to a fine powder and extracted as described above. After centrifugation the clear supernatant was acidified with $37.5 \mu \mathrm{l}$ concentrated formic acid and loaded on a $500 \mathrm{mg}$ LiCrolute RP-18 conditioned with $3 \mathrm{ml}$ ACN and $3 \mathrm{ml}$ water. The column was washed with $3 \mathrm{ml}$ water and eluted with $3 \mathrm{ml} 50 \mathrm{mM}$ TRIC/ $\mathrm{HCl} \mathrm{pH} 8.0$ in $20 \%$ $\mathrm{ACN}$. The eluate was evaporated in the vacuum to dryness, dissolved in $200 \mu \mathrm{l}$ water and injected into a HPLC system equipped with a Nucleosil 100-5 C18 $200 \times 4.6 \mathrm{~mm}$ column (Macherey-Nagel, Düren, Germany) preceded by a C18 $4 \times 3 \mathrm{~mm}$ Security Guard Cartridge (Phenomex, Aschaffenburg, Germany). Elution was started with an isocratic flow of $1 \mathrm{ml} / \mathrm{min}$ of solvent A (20 mM acetic acid set to $\mathrm{pH} 4.8$ with $\mathrm{NaOH}$ in $15 \% \mathrm{ACN}$ ) for 1 min before the concentration of solvent $B(20 \mathrm{mM}$ acetic acid set to
pH 4.8 with $\mathrm{NaOH}$ in $60 \% \mathrm{ACN}$ ) was raised linearly to $60 \%$ over $19 \mathrm{~min}$. Fractions were collected every $0.5 \mathrm{~min}$ and analysed for the presence of modified compounds by UV spectroscopy. Fractions containing the desired compound were pooled, evaporated to dryness and the residue was dissolved in $200 \mu \mathrm{l}$ water and injected into the same HPLC system described above except that elution was performed with a linear gradient of $90 \%$ solvent A $(0.1 \%$ acetic acid in water) and $10 \%$ solvent $\mathrm{B}(80 \% \mathrm{ACN}$ in water) to $60 \% \mathrm{~A}$ and $40 \% \mathrm{~B}$ within $20 \mathrm{~min}$ at a constant flow rate of $1 \mathrm{ml} / \mathrm{min}$. Fractions were collected and processed in the same way as described above. After evaporation the compounds were dissolved in $20 \mathrm{mM}$ TRIS/HCl $\mathrm{pH}$ 8.0. The concentrations were quantified by HPLC as described above using compound 15 as a standard and compound 14 as internal standard.

\section{Liquid chromatography-high resolution mass spectrometry}

Collected eluates were separated by HPLC using a Hypersil Gold C18 $3 \mu \mathrm{m} 150 \times 2.1 \mathrm{~mm}$ column (Thermo Fischer Scientific, Vienna, Austria) preceded by a C18 $4 \times 2 \mathrm{~mm}$ guard column (Phenomex, Aschaffenburg, Germany). A constant flow rate of $1 \mathrm{ml} / \mathrm{min}$ was maintained with a gradient with eluent A ( $0.1 \%$ formic acid in water) and eluent $\mathrm{B}(0.1 \%$ formic acid in $\mathrm{ACN})$. Elution started isocratic with $90 \%$ A and 10\% B for one minute. Subsequently, B was linearly raised to $100 \%$ within $19 \mathrm{~min}$ and then kept at $100 \%$ for further 2 minutes prior reducing it to the starting conditions within $0.1 \mathrm{~min}$. The column was finally equilibrated for 7.9 min with $90 \% \mathrm{~A}$ and $10 \% \mathrm{~B}$ before the next sample was injected. For detection a LTQ Orbitrap $\mathrm{XL}$ high-resolution mass spectrometer (Thermo Fisher Scientific) was used. n-BBS (n-butylbenzenesulfonamide) was constitutively present in our system and was used as lock-mass $\left([\mathrm{n}-\mathrm{BBS}+\mathrm{H}]^{+} ; m / z\right.$ of 214.08963). Chemical formulas were calculated with Xcalibur 2.1.1 with the following numbers of atoms: C: 0-30; H: 0-60; O: 1-10; N: 1-10; I: 0-2.

\section{Amino acid analysis}

Compound P2 was hydrolysed with $6 \mathrm{M}$ hydrochloric acid at $110^{\circ} \mathrm{C}$ for $4 \mathrm{~h}$. The amino acid composition in the hydrolysate was analysed as described previously [59].

\section{Additional files}

Additional file 1: Overview about the methods used for synthesis of the compounds.

Additional file 2: Impact of the halogen substituent on the potency of the compounds.

Additional file 3: Hypocotyl elongation assays with compounds 3, 9, 14 and 18. 


\section{Additional file 4: Inhibitory effect of compounds 10 and 15 in the} protoplast system.

Additional file 5: Comparison of retention times and UV spectra of the conjugates $\mathrm{P} 1, \mathrm{P} 2$ and $\mathrm{P} 3$ with standards.

Additional file 6: Amino acid analysis of conjugate P2.

Additional file 7: Identification of plant metabolites appearing in the chromatograms of Figure 5.

\section{Competing interests}

Claudia Jonak and Wilfried Rozhon are listed as inventors on a patent related to the work described in this study, which is held by the GMI-Gregor Mendel Institute of Molecular Plant Biology.

\section{Authors' contribution}

WR conceived the study and was involved in all stages of experimental work and data analysis and drafted the manuscript. WW analysed the impact of the compounds on the hypocotyl growth and performed the western blot analysis of stably transformed plants and the kinase assay with the isolated conjugates. FB performed the liquid chromatography-high resolution mass spectrometry analysis. JM and EP participated in construct cloning, plant transformation and selection of transgenic lines. TC measured the $I_{50}$ values and performed the amino acid analysis. TS and BP participated in data analysis. CJ participated in data analysis and drafted the manuscript. All authors read and approved the final manuscript.

\section{Acknowledgments}

Thanks to Simon Unterholzner for critical reading of the manuscript. This work was supported by the Austrian Science Fund (projects P22062-B16 and P22734) and the Vienna Science and Technology Fund (WWTF) through project LS09-055.

\section{Author details}

'GMI-Gregor Mendel Institute of Molecular Plant Biology, Austrian Academy of Sciences, Vienna Biocenter, Dr. Bohr-Gasse 3, Vienna 1030, Austria.

${ }^{2}$ Biotechnology of Horticultural Crops, Technische Universität München, Liesel-Beckmann-Straße 1, Freising 85354, Germany. ${ }^{3}$ Max F. Perutz Laboratories, Department of Microbiology, Immunobiology and Genetics, University of Vienna, Vienna 1030, Austria. ${ }^{4}$ Present address: Plant Biochemistry, ETH Zürich, Universitätsstr. 2, Zürich 8092, Switzerland. ${ }^{5}$ Center for Analytical Chemistry, Department of Agrobiotechnology, University of Natural Resources and Life Sciences, Konrad Lorenz Straße 20, Tulln 3430, Austria. ${ }^{6}$ Present address: Albrecht-von-Haller-Institute of Plant Sciences, Department of Plant Cell Biology, Georg-August-University Göttingen, Julia-Lermontowa-Weg 3, Göttingen 37077, Germany. ${ }^{7}$ Department of Plant Sciences, Research Unit Plant Growth Regulation, Technische Universität München, Liesel-Beckmann-Straße 1, Freising-Weihenstephan 85354, Germany.

Received: 15 January 2014 Accepted: 17 June 2014

Published: 19 June 2014

\section{References}

1. Clouse SD: Brassinosteroid signal transduction: from receptor kinase activation to transcriptional networks regulating plant development. Plant Cell 2011, 23(4):1219-1230.

2. Choe S, Tanaka A, Noguchi T, Fujioka S, Takatsuto S, Ross AS, Tax FE, Yoshida S, Feldmann KA: Lesions in the sterol delta reductase gene of Arabidopsis cause dwarfism due to a block in brassinosteroid biosynthesis. Plant J 2000, 21(5):431-443.

3. Gachotte D, Husselstein T, Bard M, Lacroute F, Benveniste P: Isolation and characterization of an Arabidopsis thaliana cDNA encoding a delta 7-sterol-C-5-desaturase by functional complementation of a defective yeast mutant. Plant J 1996, 9(3):391-398.

4. Choe S, Noguchi T, Fujioka S, Takatsuto S, Tissier CP, Gregory BD, Ross AS, Tanaka A, Yoshida S, Tax FE, Feldmann KA: The Arabidopsis dwf7/ste1 mutant is defective in the delta7 sterol C-5 desaturation step leading to brassinosteroid biosynthesis. Plant Cell 1999, 11(2):207-221.

5. Choe S, Dilkes BP, Gregory BD, Ross AS, Yuan H, Noguchi T, Fujioka S, Takatsuto S, Tanaka A, Yoshida S, Tax FE, Feldmann KA: The Arabidopsis $d$ warf1 mutant is defective in the conversion of 24-methylenecholesterol to campesterol in brassinosteroid biosynthesis. Plant Physiol 1999, 119(3):897-907.

6. Kauschmann A, Jessop A, Koncz C, Szekeres M, Willmitzer L, Altmann T: Genetic evidence for an essential role of brassinosteroids in plant development. Plant J 1996, 9(5):701-713.

7. Choe S, Dilkes BP, Fujioka S, Takatsuto S, Sakurai A, Feldmann KA: The DWF4 gene of Arabidopsis encodes a cytochrome P450 that mediates multiple 22alpha-hydroxylation steps in brassinosteroid biosynthesis. Plant Cell 1998, 10(2):231-243.

8. Szekeres M, Nemeth K, Koncz-Kalman Z, Mathur J, Kauschmann A, Altmann T, Redei GP, Nagy F, Schell J, Koncz C: Brassinosteroids rescue the deficiency of CYP90, a cytochrome P450, controlling cell elongation and de-etiolation in Arabidopsis. Cell 1996, 85(2):171-182.

9. Li J, Nagpal P, Vitart V, McMorris TC, Chory J: A role for brassinosteroids in light-dependent development of Arabidopsis. Science 1996 272(5260):398-401.

10. Kim GT, Fujioka S, Kozuka T, Tax FE, Takatsuto S, Yoshida S, Tsukaya H: CYP90C1 and CYP90D1 are involved in different steps in the brassinosteroid biosynthesis pathway in Arabidopsis thaliana. Plant $J$ 2005, 41(5):710-721.

11. Nomura T, Kushiro T, Yokota T, Kamiya Y, Bishop GJ, Yamaguchi S: The last reaction producing brassinolide is catalyzed by cytochrome P-450 s, CYP85A3 in tomato and CYP85A2 in Arabidopsis. J Biol Chem 2005 280(18):17873-17879.

12. Li J, Chory J: A putative leucine-rich repeat receptor kinase involved in brassinosteroid signal transduction. Cell 1997, 90(5):929-938.

13. Li J, Wen J, Lease KA, Doke JT, Tax FE, Walker JC: BAK1, an Arabidopsis LRR receptor-like protein kinase, interacts with BRI1 and modulates brassinosteroid signaling. Cell 2002, 110(2):213-222.

14. Nam KH, Li J: BRI1/BAK1, a receptor kinase pair mediating brassinosteroid signaling. Cell 2002, 110(2):203-212.

15. Tang W, Kim TW, Oses-Prieto JA, Sun Y, Deng Z, Zhu S, Wang R, Burlingame $A L$, Wang $Z Y$ : BSKs mediate signal transduction from the receptor kinase BRI1 in Arabidopsis. Science 2008, 321:557-560.

16. Kim TW, Guan S, Sun Y, Deng Z, Tang W, Shang JX, Sun Y, Burlingame AL, Wang ZY: Brassinosteroid signal transduction from cell-surface receptor kinases to nuclear transcription factors. Nat Cell Biol 2009, 11(10):1254-1260.

17. Jonak C, Hirt H: Glycogen synthase kinase 3/SHAGGY-like kinases in plants: an emerging family with novel functions. Trends Plant Sci 2002, 7(10):457-461.

18. Li J, Nam KH: Regulation of brassinosteroid signaling by a GSK3/SHAGGYlike kinase. Science 2002, 295(5558):1299-1301.

19. Perez-Perez JM, Ponce MR, Micol JL: The UCU1 Arabidopsis gene encodes a SHAGGY/GSK3-like kinase required for cell expansion along the proximodistal axis. Dev Biol 2002, 242(2):161-173.

20. Rozhon W, Mayerhofer J, Petutschnig E, Fujioka S, Jonak C: ASKtheta, a group-III Arabidopsis GSK3, functions in the brassinosteroid signalling pathway. Plant J 2010, 62(2):215-223.

21. Vert G, Chory J: Downstream nuclear events in brassinosteroid signalling. Nature 2006, 441(7089):96-100.

22. Dal Santo S, Stampfl H, Krasensky J, Kempa S, Gibon Y, Petutschnig E, Rozhon W, Heuck A, Clausen T, Jonak C: Stress-induced GSK3 regulates the redox stress response by phosphorylating glucose-6-phosphate dehydrogenase in Arabidopsis. Plant Cell 2012, 24(8):3380-3392.

23. Piao HL, Lim JH, Kim SJ, Cheong GW, Hwang I: Constitutive overexpression of AtGSK1 induces $\mathrm{NaCl}$ stress responses in the absence of $\mathrm{NaCl}$ stress and results in enhanced $\mathrm{NaCl}$ tolerance in Arabidopsis. Plant J 2001, 27(4):305-314.

24. Yin Y, Wang ZY, Mora-Garcia S, Li J, Yoshida S, Asami T, Chory J: BES1 accumulates in the nucleus in response to brassinosteroids to regulate gene expression and promote stem elongation. Cell 2002, 109(2):181-191.

25. Wang ZY, Nakano T, Gendron J, He J, Chen M, Vafeados D, Yang Y, Fujioka S, Yoshida S, Asami T, Chory J: Nuclear-localized BZR1 mediates brassinosteroidinduced growth and feedback suppression of brassinosteroid biosynthesis. Dev Cell 2002, 2(4):505-513.

26. Yin $Y$, Vafeados D, Tao Y, Yoshida S, Asami T, Chory J: A new class of transcription factors mediates brassinosteroid-regulated gene expression in Arabidopsis. Cell 2005, 120(2):249-259.

27. Ye H, Li L, Guo H, Yin Y: MYBL2 is a substrate of GSK3-like kinase BIN2 and acts as a corepressor of BES1 in brassinosteroid signaling pathway in Arabidopsis. Proc Natl Acad Sci U S A 2012, 109(49):20142-20147. 
28. Gudesblat GE, Schneider-Pizoń J, Betti C, Mayerhofer J, Vanhoutte I, van Dongen W, Boeren S, Zhiponova M, de Vries S, Jonak C, Russinova E: SPEECHLESS integrates brassinosteroid and stomata signalling pathways. Nat Cell Biol 2012, 14(5):548-554.

29. Poppenberger B, Rozhon W, Khan M, Husar S, Adam G, Luschnig C, Fujioka $\mathrm{S}$, Sieberer T: CESTA, a positive regulator of brassinosteroid biosynthesis. EMBO J 2011, 30(6):1149-1161.

30. Kim TW, Michniewicz M, Bergmann DC, Wang ZY: Brassinosteroid regulates stomatal development by GSK3-mediated inhibition of a MAPK pathway. Nature 2012, 482:419-422.

31. Khan M, Rozhon W, Bigeard J, Pflieger D, Husar S, Pitzschke A, Teige M, Jonak C, Hirt H, Poppenberger B: Brassinosteroid-regulated GSK3/Shaggy-like kinases phosphorylate mitogen-activated protein (MAP) kinase kinases, which control stomata development in Arabidopsis thaliana. J Biol Chem 2013, 288(11):7519-7527.

32. Rozhon W, Husar S, Kalaivanan F, Khan M, Idlhammer M, Shumilina D, Lange T, Hoffmann T, Schwab W, Fujioka S, Poppenberger B: Genetic variation in plant CYP51s confers resistance against voriconazole, a novel inhibitor of brassinosteroid-dependent sterol biosynthesis. PLoS One 2013, 8(1):e53650.

33. Min YK, Asami T, Fujioka S, Murofushi N, Yamaguchi I, Yoshida S: New lead compounds for brassinosteroid biosynthesis inhibitors. Bioorg Med Chem Lett 1999, 9(3):425-430

34. Sekimata K, Han SY, Yoneyama K, Takeuchi Y, Yoshida S, Asami T: A specific and potent inhibitor of brassinosteroid biosynthesis possessing a dioxolane ring. J Agric Food Chem 2002, 50(12):3486-3490.

35. Asami T, Mizutani M, Fujioka S, Goda H, Min YK, Shimada Y, Nakano T, Takatsuto S, Matsuyama T, Nagata N, Sakata K, Yoshida S: Selective interaction of triazole derivatives with DWF4, a cytochrome P450 monooxygenase of the brassinosteroid biosynthetic pathway, correlates with brassinosteroid deficiency in planta. J Bio/ Chem 2001, 276(28):25687-25691.

36. Sekimata K, Ohnishi T, Mizutani M, Todoroki Y, Han SY, Uzawa J, Fujioka S, Yoneyama K, Takeuchi Y, Takatsuto S, Sakata K, Yoshida S, Asami T: Brz220 interacts with DWF4, a cytochrome P450 monooxygenase in brassinosteroid biosynthesis, and exerts biological activity. Biosci Biotechnol Biochem 2008, 72(1):7-12.

37. Tanaka K, Asami T, Yoshida S, Nakamura Y, Matsuo T, Okamoto S: Brassinosteroid homeostasis in Arabidopsis is ensured by feedback expressions of multiple genes involved in its metabolism. Plant Physiol 2005, 138(2):1117-1125.

38. Kim HB, Kwon M, Ryu H, Fujioka S, Takatsuto S, Yoshida S, An CS, Lee I, Hwang I, Choe S: The regulation of DWARF4 expression is likely a critical mechanism in maintaining the homeostasis of bioactive brassinosteroids in Arabidopsis. Plant Physiol 2006, 140(2):548-557.

39. Goda H, Shimada Y, Asami T, Fujioka S, Yoshida S: Microarray analysis of brassinosteroid-regulated genes in Arabidopsis. Plant Physiol 2002, 130(3):1319-1334.

40. Shi YH, Zhu SW, Mao XZ, Feng JX, Qin YM, Zhang L, Cheng J, Wei LP, Wang $Z Y$, Zhu YX: Transcriptome profiling, molecular biological, and physiological studies reveal a major role for ethylene in cotton fiber cell elongation. Plant Cell 2006, 18(3):651-664.

41. Symons GM, Davies C, Shavrukov Y, Dry IB, Reid JB, Thomas MR: Grapes on steroids. Brassinosteroids are involved in grape berry ripening Plant Physio/ 2006, 140(1):150-158.

42. Sekimata K, Kimura T, Kaneko I, Nakano T, Yoneyama K, Takeuchi Y, Yoshida S, Asami T: A specific brassinosteroid biosynthesis inhibitor, Brz 2001: evaluation of its effects on Arabidopsis, cress, tobacco, and rice. Planta 2001, 213(5):716-721.

43. Hartwig T, Corvalan C, Best NB, Budka JS, Zhu JY, Choe S, Schulz B: Propiconazole is a specific and accessible brassinosteroid (BR) biosynthesis inhibitor for arabidopsis and maize. PLoS One 2012, 7(5):e36625.

44. Oh K, Yamada K, Asami T, Yoshizawa Y: Synthesis of novel brassinosteroid biosynthesis inhibitors based on the ketoconazole scaffold. Bioorg Med Chem Lett 2012, 22(4):1625-1628.

45. Klein PS, Melton DA: A molecular mechanism for the effect of lithium on development. Proc Natl Acad Sci U S A 1996, 93(16):8455-8459.

46. Stambolic V, Ruel L, Woodgett JR: Lithium inhibits glycogen synthase kinase- 3 activity and mimics wingless signalling in intact cells. Curr Biol 1996, 6(12):1664-1668

47. Yan Z, Zhao J, Peng P, Chihara RK, Li J: BIN2 functions redundantly with other Arabidopsis GSK3-like kinases to regulate brassinosteroid signaling. Plant Physiol 2009, 150(2):710-721
48. Peng P, Yan Z, Zhu Y, Li J: Regulation of the Arabidopsis GSK3-like kinase BRASSINOSTEROID-INSENSITIVE 2 through proteasome-mediated protein degradation. Mol Plant 2008, 1(2):338-346.

49. Zhang $S$, Cai Z, Wang $X$ : The primary signaling outputs of brassinosteroids are regulated by abscisic acid signaling. Proc Natl Acad Sci U S A 2009, 106(11):4543-4548.

50. Bain J, Plater L, Elliott M, Shpiro N, Hastie CJ, McLauchlan H, Klevernic I, Arthur JS, Alessi DR, Cohen P: The selectivity of protein kinase inhibitors: a further update. Biochem J 2007, 408(3):297-315.

51. Wallacea A, Romneya EM, Chaa JW, Chaudhrya FM: Lithium toxicity in plants. Comm Soil Sci Plant Anal 1977, 8(9):773-780.

52. Naranjo MA, Romero C, Bellés JM, Montesinos C, Vicente O, Serrano R: Lithium treatment induces a hypersensitive-like response in tobacco. Planta 2003, 217(3):417-424.

53. Zhu JK, Liu J, Xiong L: Genetic analysis of salt tolerance in arabidopsis. Evidence for a critical role of potassium nutrition. Plant Cell 1998, 10(7):1181-1191.

54. De Rybel B, Audenaert D, Vert G, Rozhon W, Mayerhofer J, Peelman F, Coutuer S, Denayer T, Jansen L, Nguyen L, Vanhoutte I, Beemster GT, Vleminckx K, Jonak C, Chory J, Inzé D, Russinova E, Beeckman T: Chemical inhibition of a subset of Arabidopsis thaliana GSK3-like kinases activates brassinosteroid signaling. Chemistry \& biology 2009, 16(6):594-604.

55. Clouse SD, Langford M, MCMorris TC: A brassinosteroid-insensitive mutant in Arabidopsis thaliana exhibits multiple defects in growth and development. Plant Physiol 1996, 111(3):671-678.

56. Fujioka S, Li J, Choi YH, Seto H, Takatsuto S, Noguchi T, Watanabe T, Kuriyama H, Yokota T, Chory J, Sakurai A: The Arabidopsis deetiolated2 mutant is blocked early in brassinosteroid biosynthesis. Plant Cell 1997, 9(11):1951-1962.

57. Zhao Y, Chow TF, Puckrin RS, Alfred SE, Korir AK, Larive CK, Cutler SR: Chemical genetic interrogation of natural variation uncovers a molecule that is glycoactivated. Nat Chem Biol 2008, 3(11):716-721.

58. Knoop F: Der Abbau aromatischer Fettsäuren im Tierkörper. Beitr Chem Physiol Pathol 1904, 6:150-162.

59. Spiess GM, Zolman BK: Peroxisomes as a source of auxin signaling molecules. Subcell Biochem 2013, 69:257-281.

60. White RH, Liebl RA, Hymowitz T: Examination of 2,4-D tolerance in perennial Glycine species. Pest Biochem Physiol 1990, 38(2):153-161.

61. Davidonis $\mathrm{GH}$, Hamilton $\mathrm{RH}$, Mumma RO: Comparative metabolism of 2,4-dichlorophenoxyacetic acid in cotyledon and leaf callus from two varieties of soybean. Plant Physiol 1980, 65(1):94-97.

62. Fujisawa T, Matoba Y, Katagi T: Application of separated leaf cell suspension to xenobiotic metabolism in plant. J Agric Food Chem 2009, 57(15):6982-6989.

63. Sinlapadech T, Stout J, Ruegger MO, Deak M, Chapple C: The hyper-fluorescent trichome phenotype of the brt1 mutant of Arabidopsis is the result of a defect in a sinapic acid:UDPG glucosyltransferase. Plant J 2007, 49(4):655-668.

64. Lehfeldt C, Shirley AM, Meyer K, Ruegger MO, Cusumano JC, Viitanen PV, Strack D, Chapple C: Cloning of the SNG1 gene of Arabidopsis reveals a role for a serine carboxypeptidase-like protein as an acyltransferase in secondary metabolism. Plant Cell 2000, 12(8):1295-1306.

65. Kim HB, Schaller H, Goh CH, Kwon M, Choe S, An CS, Durst F, Feldmann KA, Feyereisen R: Arabidopsis cyp51 mutant shows postembryonic seedling lethality associated with lack of membrane integrity. Plant Physiol 2005, 138(4):2033-2047.

66. Taiz L, Zeiger E: Plant Physiology. 4th edition. Sunderland, Massachusettes: Sinauer Associates, Inc; 2006.

67. Kramer EM, Bennett MJ: Auxin transport: a field in flux. Trends Plant SCi 2006, 11(8):382-386.

68. Korte F, Kvesitadze G, Ugrekhelidze D, Gordeziani M, Khatisashvili G, Buadze $\mathrm{O}$, Zaalishvili G, Coulston F: Organic toxicants and plants. Ecotoxicol Environ Saf 2000, 47(1):1-26.

doi:10.1186/1471-2229-14-172

Cite this article as: Rozhon et al:: Bikinin-like inhibitors targeting GSK3/ Shaggy-like kinases: characterisation of novel compounds and elucidation of their catabolism in planta. BMC Plant Biology 2014 14:172. 